\title{
Produção de Bioetanol Utilizando Microalgas: Uma Revisão
}

\author{
Bioethanol Production Using Microalgae: A Review
}

\author{
Francisco Gerhardt Magro ${ }^{1}$, Andressa Decesaro², Ritielli Berticelli ${ }^{3}$, Luciane Maria Colla ${ }^{4}$
}

\section{Resumo}

A busca por biocombustíveis foi impulsionada nas ultimas décadas devido à preocupação com o esgotamento das fontes enérgicas não renováveis. Essa revisão de literatura oferece uma abordagem da aplicação de microrganismos para a produção de bioetanol, com ênfase para as microalgas. A elevada eficiência de conversão fotossintética, o rápido crescimento, a possibilidade de manipulação do meio de cultivo a fim de produzir biomassa com elevado teor de lípidos e carboidratos, e o uso de áreas com baixa aptidão agrícola fazem das microalgas uma das matérias primas mais promissoras para a produção de biocombustíveis. A existência de uma grande variedade de métodos para a obtenção de biomassa microalgal e posterior produção de bioetanol, estimulou diversos estudos para aumentar o potencial de produção e aperfeiçoar o processo. Estudos apontam que para a produção de bioetanol atingir viabilidade econômica, a produção da biomassa algal deve objetivar ainda a obtenção de outros compostos, de maior valor agregado, como pigmentos, proteínas, ácidos graxos poli-insaturados, obedecendo ao conceito das biorrefinarias integradas.

Palavras-chave: Biocombustíveis. Microrganismo. Biorrefinarias.

\begin{abstract}
The search for biofuels has been driven in recent decades due to concern over the depletion of nonrenewable energetic sources. This literature review provides an approach to the application of microorganisms for the production of bioethanol, with emphasis on microalgae. The high efficiency of photosynthetic conversion, rapid growth, the possibility of manipulation of the medium to produce biomass with high fat and carbohydrates, and the use of areas with low agricultural potential of microalgae are one of the most promising raw materials for the production of biofuels. The existence of a large variety of methods for obtaining microalgal and subsequent production of bioethanol, biomass stimulated numerous studies to increase the production potential and improve the process. Studies show that for the production of bioethanol achieve economic viability, production of algal biomass should also aim at obtaining other compounds with higher added value, such as pigments, proteins, polyunsaturated fatty acids, according to the concept of integrated biorefineries.
\end{abstract}

Keywords: Biofuels. Microorganism. Biorefinery.

\footnotetext{
${ }^{1}$ Engenheiro Ambiental. Discente do Programa de Pós-Graduação em Engenharia Civil e Ambiental, Universidade de Passo Fundo; Email: chicomagro2@hotmail.com

${ }^{2}$ Engenheiro Ambiental. Discente do Programa de Pós-Graduação em Engenharia Civil e Ambiental, Universidade de Passo Fundo; Email: 91526@upf.br

${ }^{3}$ Engenheiro Ambiental. Discente do Programa de Pós-Graduação em Engenharia Civil e Ambiental, Universidade de Passo Fundo; Email: 100480@upf.br

${ }^{4}$ Docente permanente do Programa de Pós-Graduação em Engenharia Civil e Ambiental, Universidade de Passo Fundo. Endereço: Campus I, BR 285, km 171, CP 611, 99001-970 Passo Fundo - RS, Brasil; Email: lmcolla@upf.br. Fone: +55-43-3316-8193

*Autor para correspondência
} 


\section{Introdução}

O crescimento acelerado da população mundial, associada a uma busca por serviços e produtos, causam preocupações ambientais em função da demasiada utilização de recursos naturais. Entre esses recursos destacam-se os combustíveis fósseis, como o petróleo e gás natural. Esses combustíveis ocupam 87\% da energia primária consumida no mundo (WORLD ECONOMIC FORUM, 2013). Conforme Vasudevan e Fu (2010), com o consumo atual, as reservas mundiais de petróleo estarão exauridas em 40 anos, e de gás em 60 anos.

Como as fontes de combustíveis não renováveis tendem a se esgotar, a busca por fontes energéticas renováveis foi impulsionada nas últimas décadas, surgindo assim de maneira viável os biocombustíveis líquidos de primeira, segunda e terceira geração.

Os biocombustíveis de primeira geração são produzidos a partir de açúcares, grãos e sementes, e requerem um processo simples de produção. A primeira geração mais conhecida de biocombustíveis é o etanol, que é extraído pela fermentação do açúcar de plantas cultivadas e amido contido em grãos de milho (AMORIM et al., 2011; CANAKCI; SANLI, 2008; MOSER; VAUGHN, 2012; SOUZA et al., 2014), e o biodiesel produzido a partir de plantas oleaginosas como a mamona e grãos de soja (DANTAS et al., 2011; ESCOBAR et al., 2009; SAVALIYA; DHORAJIYA; DHOLAKIYA, 2013).

Os biocombustíveis de segunda geração são produzidos pelo processamento da biomassa celulósica de plantas (SAVALIYA; DHORAJIYA; DHOLAKIYA, 2013; SOCCOL, 2009). Para a obtenção de biocombustíveis de primeira e segunda geração, há a necessidade de áreas agricultáveis para a obtenção da matéria prima, o que é um inconveniente, já que competem com a produção de alimento (GISELRØD; PATIL, 2008).

Os biocombustíveis de terceira geração são os obtidos através da biomassa de microrganismos, em especial de microalgas. Essa ideia surgiu na década de 50 e esforços foram concentrados com esse fim na década 70 (CHEN et al., 2009; VARFOLOMEEV; WASSERMAN, 2011). As justificativas para a produção de biocombustíveis microalgais em comparação com os de primeira e segunda geração são que o cultivo pode ser realizado em terras com baixo potencial agrícola e, portanto, pode reduzir a competição por terras agricultáveis. Além disso, geram-se novas oportunidades econômicas para zonas árida, secas ou afetadas pela salinidade (SCHENK et al., 2008).

A partir da biomassa microalgal podem ser produzidos os dois tipos de biocombustíveis líquidos, o bioetanol através da sacarificação dos carboidratos da biomassa (MIRANDA; PASSARINHO; GOUVEIA, 2012) e o biodiesel através dos lipídios (CHISTI, 2008; GONG; JIANG, 2011). Objetivouse realizar uma revisão de literatura da aplicação de microrganismos para a produção de bioetanol, com ênfase para as microalgas.

\section{Microalgas como matéria prima para a produção de bioetanol}

Estudos recentes têm demonstrado que algumas espécies microbianas, tais como leveduras, fungos, e microalgas podem ser usadas como matérias primas potenciais para a produção de biodiesel e bioetanol, devido à capacidade das mesmas de armazenar grandes quantidades de lipídios e carboidratos na sua biomassa (CHISTI, 2008; DRAGONE et al., 2011; TSIGIE et al., 2013). A maioria dos estudos é em relação à produção de biocombustíveis de microalgas (CHISTI, 2008; DRAGONE et al., 2011; YEH; CHANG, 2011; RISMANI et al., 2011, HO et al., 2013). Margarites (2014), em experimentos de produção de etanol a partir de biomassa de Spirulina sp., apresentou produtividade de 1,18 g. $\mathrm{L}^{-1} \cdot \mathrm{h}^{-1}$ de etanol, utilizando $50 \%$ dos carboidratos provindos da sacarificação da biomassa e $50 \%$ a partir da glicose. 
Fatores como a elevada eficiência de conversão fotossintética, o rápido crescimento, o elevado teor de lípidos e carboidratos, fazem das microalgas uma das matérias-primas mais promissoras para a produção de biodiesel e bioetanol (CHISTI, 2008; ABREU et al., 2012). Segundo Chisti (2007), a produtividade de óleo das microalgas é cerca de 8 a 20 vezes superior à produtividade de óleo das culturas energéticas terrestre.

Além dessas vantagens as microalgas também possuem a capacidade de modificação da composição bioquímica das células através da variação das condições de crescimento, e a possibilidade de utilizar $\mathrm{CO}_{2}$ dos gases de combustão de centrais elétricas ou outras fontes industriais para aumentar a taxa de crescimento (STEPHENSON et al., 2010).

\section{Condições para produção da biomassa microalgal}

Os microrganismos requerem condições de cultivo adequadas para crescer, com melhores condições de cultivo maior é a taxa de crescimento e produtividade (FERNANDEZ et al., 2013).

O cultivo de microalgas requer condições ambientais específicas, que variam de espécie para espécie. Os parâmetros principais que influenciam a produção de biomassa incluem intensidade da luz e comprimento de onda adequado, a temperatura, a concentração de $\mathrm{CO}_{2}$, a quantidade de nutrientes, condições de mistura e contaminação (SINGH; DHAR, 2011).

Além da água, um dos fatores mais importantes para o crescimento microbiano é o carbono. O carbono é o esqueleto estrutural da matéria viva, ele é necessário para todos compostos orgânicos que constituem uma célula viva.

$\mathrm{O} \mathrm{CO}_{2}$ está presente no ar atmosférico em baixas concentrações o que pode limitar o crescimento rápido, e como cerca de $45 \%$ a $50 \%$ da biomassa das microalgas é de carbono, muitas vezes é necessário suplementar este carbono para que se possa atingir uma taxa de crescimento maior. Este $\mathrm{CO}_{2}$ é geralmente misturado com ar em culturas gaseificadas ou injetado nas culturas de microalgas através de vasos de troca gasosa em fotobiorreatores ou tanques abertos (DOUCHA; STRAKA; LIVANSKY , 2005; CHAE; HWANG; SHIN, 2006)

A fonte de energia de base para as microalgas fotoautotróficas é disponibilidade e a intensidade da luz, sendo este um dos principais parâmetros que afetam o sucesso ou fracasso de culturas das microalgas. Com o aumento da intensidade de luz, aumenta a fotossíntese até que um ponto é alcançado onde a taxa máxima de crescimento é atingida (ponto de saturação) (RICHMOND, 2000; LEE, 2001). O aumento da intensidade da luz para além deste ponto não aumenta a taxa de crescimento e pode levar à foto-oxidação, danificando os receptores de luz diminuindo a velocidade de fotossíntese e produtividade (fotoinibição) (SINGH; DHAR, 2011).

Outro parâmetro que afeta o crescimento é a temperatura, que se geralmente aumentada conduz a um aumento exponencial do crescimento das microalgas, até que um nível ótimo seja atingido, após o crescimento diminui. Para culturas ao ar livre e sistemas abertos, a capacidade de controlar as temperaturas é muitas vezes é limitado, e é determinado pela temperatura atmosférica, radiação solar, e umidade. A flutuação na temperatura ambiente podem resultar em temperaturas diurnas com diferenças de até $20^{\circ} \mathrm{C}$ para as noturnas, o que pode afetar a produtividade (OLAIZOLA, 2000).

Além do carbono, os microrganismos necessitam de outros nutrientes como nitrogênio, enxofre, fósforo, potássio, magnésio, cálcio e sódio. E requerem quantidades muito pequenas de elementos traços (micronutrientes), como ferro, cobre, molibdênio e zinco. Embora necessários em pequeníssimas quantidades, os elementos traços são fundamentais para o funcionamento celular adequado (TORTORA; FUNKE; CASE, 2012). 
Para o crescimento ótimo das microalgas é necessária uma série de nutrientes, que dependendo das espécies requerem variações. Quanto aos macronutrientes, as microalgas requerem carbono $(\mathrm{C})$, nitrogênio( $\mathrm{N})$, oxigênio $(\mathrm{O})$, hidrogênio $(\mathrm{H})$ e fósforo $(\mathrm{P})$, além de cálcio $(\mathrm{Ca})$, magnésio $(\mathrm{Mg})$, enxofre $(\mathrm{S})$ e potássio $(\mathrm{K})$. Como micronutrientes, geralmente requerem ferro $(\mathrm{Fe})$, manganês $(\mathrm{Mn})$, cobre $(\mathrm{Cu})$, molibdênio ( $\mathrm{Mo})$ e cobalto $(\mathrm{Co})$, enquanto algumas microalgas também necessitam baixas concentrações de vitaminas no meio de cultura. As microalgas de uma mesma espécie possuem diferentes quantidades de proteínas, carboidratos e lipídeos, quando cultivadas em meios com diferentes quantidades de nutrientes (PROCHÁZKOVÁ et al., 2014).

A contaminação por espécies indesejáveis principalmente no sistema de tanques aberto é outro parâmetro que afeta a taxa de crescimento. Quando um tanque aberto é inoculado com a cepa desejada de microalgas com o objetivo de iniciar o crescimento e dominar a flora da lagoa, pode acontecer de que algumas espécies indesejadas sejam inevitavelmente introduzidas, reduzindo o rendimento e competindo com as espécies inoculadas (SCHENK et al., 2008).

Em concentrações elevadas de algas, quase toda a luz disponível é absorvida somente por uma fina camada superior de células nos reatores, que pode ser evitada por meio de uma agitação adequada. A agitação deve ser suficiente para manter as células de algas em suspensão, proporcionar uma exposição uniforme de luz em todas as células, aumentar a transferência de massa para reduzir o gradiente de nutriente na cultura e para evitar a sedimentação das células. No entanto, o fornecimento de energia excessiva pode produzir danos celulares as microalgas que são suscetíveis às forças de cisalhamento, afetando o desempenho da cultura (MOLINA; FERNANDEZ; CHISTI, 2001).
Potencial de conversão das microalgas em bioetanol

O potencial de conversão de biomassa algal em bioetanol está primeiramente ligado à obtenção de grandes quantidades de biomassa com elevado teor de carboidratos. O crescimento microalgal é dependente da realização da fotossíntese, que é um processo metabólico pelo qual os organismos fotoautotróficos são capazes de converter energia luminosa em energia química na forma de carboidratos (CHEN et al., 2009; MIRANDA; PASSARINHO; GOUVEIA, 2012).

Duas fases distintas podem ser identificadas durante a fotossíntese: a fase clara e a fase escura. $\mathrm{Na}$ fase clara, ocorre a interação dos fótons da luz com os pigmentos fotossintéticos presentes no fotossistema II. Esta interação ocasiona a oxidação da clorofila, que doa elétrons para compostos presentes em uma cadeia de transporte de elétrons presente na membrana tilacóide. O fluxo de elétrons gera um fluxo de prótons que é utilizado para a síntese de ATP pela enzima ATPsintase. Os elétrons são transferidos por citocromos para o fotossistema I, também responsável pela absorção de energia luminosa. Estes elétrons são utilizados na geração de potencial redutor na forma de NADPH (ALBERTS et al., 1997).

$\mathrm{Na}$ fase de escura, o dióxido de carbono é reduzido para carboidratos no ciclo de Calvin, utilizando a energia derivada do NADPH e ATP (ALBERTS et al., 1997).

$\mathrm{O} \mathrm{CO}_{2}$ condensa-se com a ribulose-1,5-bifosfato (RUBP), formando um composto instável, com seis carbonos, que é rapidamente hidrolisado a duas moléculas de 3-fosfoglicerato pela enzima ribulose 1,5-bisfosfato carboxilase/oxigenasse. Uma das moléculas de 3-fosfoglicerato é utilizada como substrato para a formação de carboidratos, enquanto a outra é usada na regeneração da ribulose-1,5 bifosfato. Os carboidratos são formados dentro do cloroplasto, mas também no citosol (MARKOU; ANGELIDAKI; GEORGAKAKIS, 2012). 
Figura 1 - Ciclo de Calvin

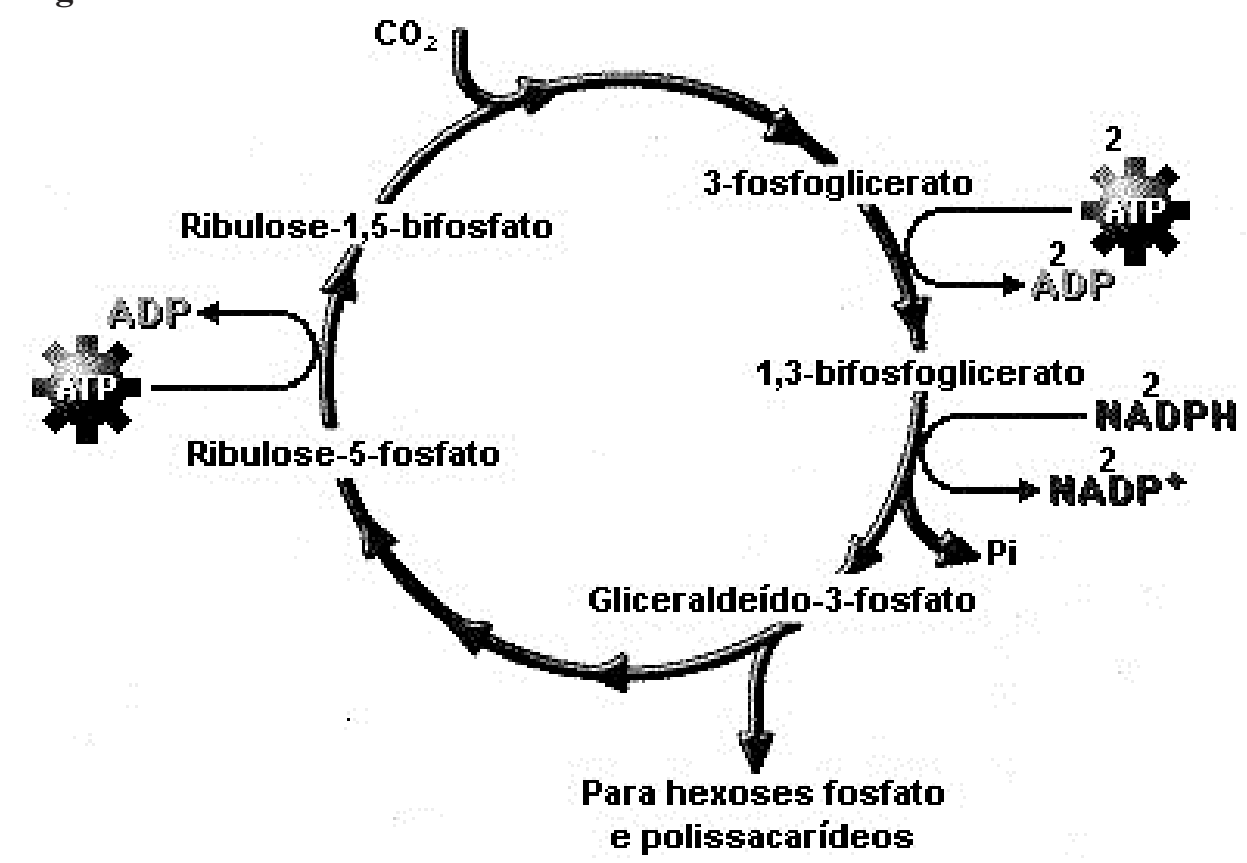

Fonte: Wells e Tupy (1988).

A produção de carboidratos serve a dois objetivos principais para as microalgas, atuam como componentes estruturais nas paredes celulares, e como componentes de armazenamento no interior da célula. Os carboidratos, como os compostos armazenados, fornecem a energia necessária para os processos metabólicos dos organismos e para permitir, se necessário, a sobrevivência temporária em ambientes escuros (GEIDER; LA ROCHE, 2002).

Para obter uma maior quantidade de biomassa das microalgas rica em açúcar, que é utilizada como matéria-prima para a produção de bioetanol, a produtividade de carboidratos na célula deve ser alta.

A porcentagem de carboidratos na biomassa depende das espécies de microalgas e das condições de cultivo e ambientais. Várias espécies de microalgas, tais como Porphyridium cruentum (40\% - 57\%), Spirogyra sp. (33\% - 64\%), têm um teor elevado de carboidratos (HARUN et al., 2010). As microalgas como Chlorella vulgaris, Chlamydomona reinhardtii, Dunaliella tertiolecta, Scenedesmus acutus e Tetraselmisem subcordiformis apresentaram em estudos a capacidade de acumular uma grande quantidade de carboidratos ( $>40 \%$ do peso seco) (JOHN et al., 2011; RAZEGHIFARD, 2013). Pesquisadores relataram que o gênero de Chlorella possui um elevado teor de carboidratos, especialmente as espécies de C. vulgaris, com carboidratos de $37 \%$ - 55\% do seu peso seco (BRENNAN; OWENDE, 2010; DRAGONE et al., 2011).

No entanto, para a produção de biocombustíveis ser maximizada, o elevado teor de carboidrato tem de ser combinado com a capacidade das espécies de microalgas a ter elevada produção de biomassa. Portanto, as espécies conhecidas de microalgas que possuem taxas elevadas de crescimento podem ser manipuladas para produzir os maiores valores de carboidratos (MARKOU; ANGELIDAKI; GEORGAKAKIS, 2012). A produtividade em carboidratos nos cultivos (g.L$\left.{ }^{1} \cdot d^{-1}\right)$ pode ser obtida de acordo com a Equação 1 (MARGARITES, 2014): 
Produtividade em carboidratos $\left(\mathrm{g} . \mathrm{L}^{-1} \cdot \mathrm{d}^{-1}\right)=\frac{\mathrm{X}_{\mathrm{f}} \times \mathrm{CHO}}{100 \times \mathrm{t}_{\mathrm{c}}}$

Em que, $X_{f}$ representa a concentração final de biomassa (g.L $\left.\mathrm{L}^{-1}\right), \mathrm{CHO}$ representa a concentração de carboidratos $(\%)$, e o $t_{c}$ representa o tempo de cultivo (d).

O controle do cultivo ou nas condições ambientais é a forma comumente utilizada para a manipulação da composição da biomassa de microalgas, e maior acumulação de carboidratos na biomassa. Os cultivo e fatores ambientais mais frequentemente relatados, que afetam o teor de carboidratos, são o tipo e a concentração da fonte de nutrientes, intensidade de luz e temperatura. Além disso, o modo metabólico (autotróficos, heterotróficos, e mixotróficos) afeta a composição da biomassa (MARKOU; ANGELIDAKI; GEORGAKAKIS, 2012).

A estratégia de limitação de nutrientes é considerada como sendo uma abordagem razoável para a produção de microalgas rica em carboidrato. Esta técnica é exequível porque é relativamente fácil de controlar os nutrientes no meio de cultura (DRAGONE et al., 2011; MARKOU; ANGELIDAKI; GEORGAKAKIS, 2012).

Vários estudos recentes têm demonstrado que o cultivo sob condições deficientes de nitrogênio eleva o teor de lipídios ou carboidratos, porque o nitrogênio em condição de esgotamento favorece que as proteínas ou peptídeos acumulados no interior das células de microalgas possam ser transformados em lípidos ou carboidratos (DRAGONE et al., 2011; YEH; CHANG, 2011; HO et al., 2013). Estudos relacionados ao acúmulo de carboidratos relataram que com déficit de nitrogênio, culturas de Chlorella vulgarisa acumularam carboidratos de até 38\% 41\% (BRÁNYIKOVÁ et al., 2011; DRAGONE et al., 2011), cerca de $35 \%$ em Tetraselmis subcordiformis (JI et al., 2011), enquanto que a Spirulina platensis acumulou 55\% - 65\% de carboidratos (SASSANO et al., 2010).
O fósforo é um elemento essencial para o ATP e a restrição deste nutriente afeta a estratégia global de energia dos micro-organismos, resultando na diminuição da síntese de proteínas e acúmulo de carboidratos e/ou lipídios. Em cultivos Spirulina com limitação de fósforo, foi obtido aumento nos teores de carboidratos de $9 \%$ para $65 \%$, enquanto o teor de proteínas diminuiu de 46,5\% para $25 \%$ em cultivos semi-contínuos (MARKOU, 2012).

A concentração de dióxido de carbono afeta o acúmulo de carboidratos de microalgas. Diminuições na concentração de dióxido de carbono causaram um aumento do conteúdo de carboidratos na biomassa de microalgas (THYSSEN; SCHLICHTING; GIERSCH, 2001). Conforme Abreu et al., (2012) a Chlorella acumula mais carboidratos em condições metabólicas mixótroficas. Choix, De Bashan e Bashan (2012) obtiveram maior acúmulo de carboidratos no modo heterotrófico do que sob condições fotoautotróficas, utilizando carbono inorgânico.

Em geral é conhecido que as intensidades de luz elevada resultam em um aumento no conteúdo de carboidratos (HU, 2004). Em culturas de espécies Porphyridium, foi observado um aumento de 3 vezes de carboidrato, quando a intensidade da luz aumentou cerca de 4 vezes (FRIEDMAN; DUBINSKY; ARAD, 1991). Conforme Ho, Chen e Chang (2012), a Scenedesmus obliquus obteve a maior produção de biomassa e carboidrato com o aumento da intensidade da luz, até atingir $420 \mu \mathrm{mol}$ $\mathrm{m}^{-2} \mathrm{~s}^{-1}$, após essa intensidade ocorreu o fenômeno da fotoinibição, diminuindo a produção e o acúmulo de carboidrato.

Embora seja certo que a temperatura afeta a composição da biomassa, resultados contraditórios são relatados em diferentes espécies de microalgas. Em culturas de Spirulina sp. o aumento da temperatura de $25^{\circ} \mathrm{C}$ para $40^{\circ} \mathrm{C}$ resultou em um ligeiro aumento dos carboidratos na biomassa onde passou de 14\% para 21\% (OGBONDA; AMINIGO; ABU, 2007), enquanto que no Chaetoceros cf. 
wighamii o acúmulo de carboidratos foram maiores nas temperaturas mais baixas testadas (CASTRO ARAÚJO; GARCIA, 2005).

\section{Sistema de cultivo das microalgas}

A escolha do sistema de cultivo é um aspecto importante, que afeta significativamente a eficiência e eficácia do custo do processo de produção de biocombustíveis de microalgas (CARVALHO; MEIRELES; MALCATA, 2006; LEE, 2001).

As microalgas têm sido tradicionalmente cultivadas em fotobiorreatores abertos, como tanques abertos, devido à simplicidade e baixo custo deste tipo de design. Infelizmente, esses fotobiorreatores permitem apenas controle limitado das condições de operação. Além disso, as culturas podem ser facilmente contaminadas (FERNANDEZ et al., 2013; TREDICI, 2004). No entanto, para a produção de produtos de alto valor a partir de microalgas que não podem ser mantidas em tanques abertos, é necessário empregar sistemas fechados, tais como fotobiorreactores tubulares, que permitem o controle das condições de funcionamento, evitando contaminações (FERNANDEZ et al., 2013).

O cultivo em larga escala de microalgas em sistemas ao ar livre, tanques abertos está bem estabelecida (BOROWITZKA, 2005). Os tanques podem ser escavados e revestidos com materiais impermeáveis ou podem ser construídos com paredes, e normalmente é utilizado um sistema de pás para realizar a agitação. Os tanques abertos são adequados para um pequeno número de espécies de algas que podem tolerar as condições ambientais extremas. Tais espécies de algas incluem crescimento rápido, como a Chlorella, Spirulina e Dunaliella que prosperam em ambientes altamente alcalinos ou salinos (CHISTI, 2007).

Os problemas associados com os sistemas abertos incluem a contaminação, ambientes não controlados, a evaporação, a adequação limitada das espécies, baixas produtividades volumétricas, e a necessidade de uma grande área de terra, o que têm estimulado o desenvolvimento de fotobiorreatores fechados, a fim de superar a ineficiência dos sistemas anteriores (SINGH; DHAR, 2011).

Há dois tipos principais de fotobiorreatores fechados, são os dos tipos tubulares e em placas. Devido à estrutura fechada $\mathrm{e}$ o ambiente relativamente controlável, os fotobiorreatores fechados pode atingir alta densidade celular e são de fácil manutenção da monocultura (UGWU; AOYAGI; UCHIYAMA, 2008; LEE, 2001).

Os fotobiorreatores fechados podem ser construídos com vidro ou plástico transparente, podem ser horizontal, vertical, cónico, e inclinados. E a mistura pode ser realizada através do transporte aéreo ou sistema de bomba (UGWU; AOYAGI; UCHIYAMA, 2008). Os fotobiorreatores fechados permitem a concentração de células muito mais elevadas do que o sistema tanques abertos, devido à grande área de iluminação, e menores problemas de contaminação. As desvantagens são gradientes de $\mathrm{pH}$, oxigênio dissolvido e $\mathrm{CO}_{2}$ ao longo dos tubos, o crescimento de incrustações nas paredes e estresse hidrodinâmico (LEE, 2001; UGWU; AOYAGI; UCHIYAMA, 2008).

Existem vários relatos a respeito do design, eficiência e eficácia de custo de um processo de produção de biocombustíveis de microalgas através de tanques abertos (CHISTI, 2007; LEE, 2001). Mesmo que o sistema de tanques abertos pareça ser favorecido para o cultivo comercial de microalgas no presente devido aos seus baixos custos de capital, o sistema fechado oferece um melhor controle sobre a contaminação, a transferência de massa e outras condições de cultivo. A combinação do fotobiorreatores fechado e de tanques abertos combinam as vantagens dos dois e tem demonstrado ser eficaz (HUNTLEY; REDALJE, 2007).

\section{Processo de colheita da biomassa}

Várias tecnologias vêm sendo empregadas para a colheita da biomassa microalgal. Atualmente, 
as principais são a coagulação-floculação por adição de reagentes químicos, a centrifugação e a filtração (KHOO et al., 2011).

Segundo Lardon et al. (2009), o processo de colheita da biomassa tem sido apontado como um dos principais problemas no cultivo de microalgas, devido ao reduzido diâmetro deste tipo de biomassa (2 a $20 \mu \mathrm{m}$ ) e à sua dispersão no meio líquido, o que requer a utilização de tecnologias dispendiosas e com elevado consumo de energia.

Afloculação pode ser induzida de várias maneiras como, a floculação química, a electrofloculação, a biofloculação e outros dispositivos de flutuação com ar dissolvido. Os floculantes inorgânicos como o $\mathrm{Al}_{2}\left(\mathrm{SO}_{4}\right)_{3}$ (Sulfato de alumínio), $\mathrm{Fe}_{2}\left(\mathrm{SO}_{4}\right)_{3}$ (Sulfato férrico), $\mathrm{FeCl}_{3}$ (Cloreto férrico), ou $\mathrm{Ca}(\mathrm{OH})_{2}$ (cal) são utilizados para neutralizar ou reduzir a carga de superfície negativa das células provocando a formação de flocos (LARDON et al., 2009; HEASMAN et al., 2000).

No entanto, a floculação química possui um alto custo para ser utilizada na produção de biocombustíveis e devido à incorporação de uma grande quantidade de sais de metais na biomassa colhida limita utilização da biomassa e cria problemas de descarte do efluente (MOLINA et al., 2003). Segundo Brentner, Eckelman e Zimmerman (2011) outros coagulantes são promissores para serem utilizados, como a quitosana, que é produzida a partir de resíduos da pesca de crustáceos, sendo considerada um coagulante renovável.

O outro processo bem estabelecido no setor industrial que pode ser utilizado para a colheita da biomassa é a centrifugação que utiliza força de gravidade para realizar a separação. A morfologia e tamanhos das células a serem colhidas pode afetar a colheita (custos) com células filamentosas e células em colônia o processo é mais rápido do que com as células menores (NAKAMURA et al., 2005). No entanto o processo de centrifugação requer altos gastos de energia, o que poderia deixar inviável o processo de produção de bioetanol de microalgas (SINGH; DHAR, 2011).

A filtração também constitui uma opção tecnicamente viável para a colheita das células microalgais, que é o processo pelo qual partículas são retidas por uma tela (membrana) de acordo com o seu tamanho. A filtração pode ser realizado sob pressão, vácuo ou gravidade (MOLINA et al., 2003). Embora, os custos associados à filtração são baixos, o entupimento da tela e membrana devido à incrustação limita sua adequação à maioria das espécies de microalgas (SINGH; DHAR, 2011).

$\mathrm{Na}$ colheita da biomassa os processos podem ser aplicados em conjunto como a floculação e posterior centrifugação, sendo uma forma mais viável de realizar o processo (VASUDEVAN et al., 2012; SORATANA; HARPER; LANDIS, 2012).

\section{Etapas de produção de bioetanol a partir da} biomassa

Conforme Harun e Danquaha (2011) existem diversas metodologias para produzir o bioetanol a partir de microalgas, mas o processo mais comum se dá pelas seguintes etapas: pré-tratamento, para romper a parede celular da microalga, hidrólise do carboidrato com o intuito de formar açúcares simples e fermentação dos açúcares para posterior produção do bioetanol.

O objetivo do pré-tratamento é de alterar ou remover impedimentos estruturais e de composição para a posterior realização da hidrólise, a fim de melhorar a taxa de hidrólise e aumentar o rendimento de açúcares fermentáveis a partir de celulose ou a hemicelulose (MOSIER et al., 2005). O pré-tratamento é necessário para modificar a estrutura da biomassa celulósica, e tornar mais acessíveis as enzimas, o carboidrato que será transformado em açúcares fermentáveis (BENSAH; MENSAH, 2013). Um pré-tratamento com sucesso deve satisfazer os seguintes requisitos: melhorar a formação de açúcares ou a capacidade de formar 
posteriormente açúcares por meio de hidrólise, evitar a degradação ou perda de carboidrato, evitar a formação de subprodutos inibidores da hidrólise e subsequente do processo de fermentação e ser rentável (SILVERSTEIN, 2004).

O pré-tratamento pode ser realizado de diferentes maneiras, tais como pré-tratamento mecânico, químico ou biológico (HAMELINCK; VAN HOOIJDONK; JAAIJ, 2005; MABEE et al., 2006; LEE et al., 2010).

Outra etapa também considerada fundamental para a produção de bioetanol é a hidrólise do carboidrato (sacarificação), que constituem a parede das células de microalgas, a qual está interrelacionada com a etapa do pré-tratamento, uma vez que esse processo ajuda no rompimento da parede celular (RAZEGHIFARD, 2013).

A hidrólise do carboidrato é importante para torná-lo metabolizável pelos microrganismos que realizam a fermentação (MIRANDA, PASSARINHO; GOUVEIA, 2012). Para que isto ocorra é necessário realizar o rompimento celular liberando para o meio os produtos intracelulares das microalgas, como o lipídio e carboidrato (BRENNAN; OWENDE, 2010).

Em geral, produtos químicos ou enzimáticos são os métodos comuns utilizados para realizar a hidrólise. Embora a hidrólise ácida seja mais rápida, mais fácil e mais barata do que outros tipos de hidrólise, as condições ácidas podem levar a decomposição dos açúcares em compostos indesejados que inibem a fermentação realizada no processo seguinte de produção (MOXLEY; ZHANG, 2007; GIRIO et al., 2010; HARUN et al., 2010).

Em contraste, a hidrólise enzimática é mais lenta e muito mais cara do que a hidrólise ácida, mas é um processo eficiente para obter rendimentos mais elevados de açúcares sem a produção de produtos de inibição. Além do problema do custo, a hidrólise enzimática tem outra desvantagem de exigir prétratamentos (LYND et al., 2012).
O tratamento com ácido sulfúrico diluído a altas temperaturas (120-160 ${ }^{\circ}$ C) mostrou-se um método muito eficaz de hidrólise (HARUN; DANQUAH 2011; MIRANDA et al., 2012). A $\alpha$-amilase e enzimas glucoamilase também são usados para liberar os açúcares fermentáveis dos carboidratos complexos (SIM; CHOI; NGUYEN, 2010). A $\alpha$-amilase é uma endoenzima carboidrase com atividade hidrolítica das ligações $\alpha-1,4$ em polissacarídeos dispersos em meio aquoso, contendo, pelo menos, três resíduos de glicose na cadeia. Algumas $\alpha$-amilases apresentam atividade de hidrólise das ligações glicosídicas $\alpha-1,6$, mas com eficiência reduzida (REGULY, 1996; LIMA et al., 2001; BON; FERRARA; CORVO, 2008).

O hidrolisado obtido é então utilizado na fermentação por microrganismos, como as leveduras para produzir o bioetanol. O hidrolisado não contém só a glicose, mas também vários monossacáridos, tais como xilose, manose, galactose, arabinose, e oligossacarídeos, sendo assim para obter o sucesso na produção do bioetanol esses microrganismos devem fermentar com eficiência esses açúcares (KATAHIRA et al., 2006).

A fermentação envolve microrganismos capazes de se desenvolver em ausência de oxigênio e de qualquer outro aceptor final de elétrons exógeno. A fermentação é o termo que denota a degradação anaeróbica da glicose ou de outros nutrientes orgânicos por estes microrganismos em vários produtos para obter energia na forma de ATP (BARBOSA; TORRES, 1998; LEHNINGER; NELSON; COX, 2000). O etanol é produzido pela redução de acetaldeído gerado a partir do piruvato como um resultado da glicólise anaeróbia (RAZEGHIFARD, 2013).

Conforme Maria et al. (2009), a seleção de microrganismos no processo de fermentação deve apresentar características definidas e específicas como: capacidade de fermentar açúcares com alto desempenho, elevada velocidade de fermentação, osmotolerância, tolerância ao etanol e a compostos 
ácidos, viabilidade celular elevada, resistência a altas temperaturas e estabilidade genética.

A levedura Saccharomyces cerevisiae é comumente utilizada na fermentação alcoólica, em temperaturas de $30{ }^{\circ} \mathrm{C}$ e na presença, além da fonte de carbono, de uma fonte de nitrogênio (RAZEGHIFARD, 2013). Ela é considerada uma das mais eficazes leveduras na produção de bioetanol, e possui vantagens como a alta produção de bioetanol a partir de hexoses, elevada tolerância ao etanol e outros compostos inibidores a (BALAT; BALART; ÖZ, 2008).

Além da utilização de leveduras, outros microrganismos podem ser utilizados para o processo de fermentação. Entretanto, ainda não foram realizados muitos testes para aplicar no setor de produção de bioetanol com microalgas (CHANDER et al., 2011). As bactérias que atualmente mostram se como promissoras para a exploração industrial são Escherichia coli, Klebsiella oxytocae e Zymomonas mobilis (DIEN; COTTA; JEFFRIES, 2003). A Zymomonas mobilis é eficiente para a produção de bioetanol a partir da glicose, frutose e sacarose que são açúcares hexoses, mas não é eficiente a partir de açúcares pentoses, embora a fermentação da xilose com a Z. mobilis foi gerada através da introdução de uma via de metabolização da xilose a partir da $E$. coli (HAGERDAL et al., 2006). Essas possibilidades de uso de outros microrganismos fermentadores, além da $S$. cerevisiae, deve ser estudada no caso da obtenção de bioetanol por microalgas. Os carboidratos obtidos através da biomassa algal, bem como os resultantes dos processos de sacarificação, podem ser constituídos, além de hexoses, por pentoses, o que dificulta a utilização da somente da $S$. cerevisiae.

\section{Obtenção de biocombustíveis no contexto de biorrefinarias}

Recentes estudos indicaram que a produção de biocombustíveis de microalgas está relativamente perto de serem economicamente viáveis, dada à evolução esperada em relação às condições de mercado e tecnologia de produção (STEPHENS et al., 2010). Além dos carboidratos, considerados matéria prima para a produção de bioetanol, a biomassa de microalgas também contêm vários outros componentes valiosos, incluindo os lípidos, que podem ser convertidos em biodiesel, aos pigmentos e às proteínas, que possuem aplicações como alimentos funcionais e para a obtenção de nutracêuticos e fármacos (LAMMENS et al., 2012; YEN et al., 2013).

A melhoria da viabilidade econômica pode ser alcançada pelo acoplamento de produção de biocombustíveis com a produção simultânea de produtos de alto valor em um conceito de biorrefinaria. A integração do cultivo de microalgas com piscicultura, instalações de processamento de alimentos e estações de tratamento de águas residuais, oferece a possibilidade de processamento de resíduos através da reciclagem da matéria orgânica e, ao mesmo tempo o fornecimento de nutrientes de baixo custo (CARRIQUIRY; DU; TIMILSINA, 2011).

Vários compostos das microalgas são úteis, tais como pigmentos ( $\beta$-caroteno, astaxantina, ficobiliproteínas), ácidos graxos (ácido $\gamma$-linolénico, ácido eicosapentaenóico, ácido araquidônico), vitaminas e aminoácidos essenciais podem ser aplicados em humanos e nutrição de animais, no setor farmacêutico, cosméticos e aquicultura (CARDOZO et al., 2007; SKJÅNES; REBOURS; LINDBLAND, 2012).

Portanto, o conceitotecnológico debiorrefinarias de microalgas merece maiores investigações. Em particular, as avaliações de viabilidade econômica e de ciclo de vida de tais processos devem ser realizadas para confirmar viabilidade comercial de converter os componentes de microalgas para biocombustíveis e em outros produtos de valor comercial (YEN et al., 2013). 


\section{Considerações finais}

$\mathrm{O}$ aumento no consumo de energia e a tendência de que as fontes de combustíveis não renováveis se esgotem, impulsionaram a busca por tecnologias para produzir bioetanol de microrganismo. Devido ao seu potencial para produzir bioetanol as microalgas estão sendo largamente estudadas por diversos pesquisadores. A busca para tornar viável economicamente a produção de bioetanol a partir da biomassa microalgal, faz com que diversos estudos sejam realizados, principalmente avaliando a espécie de microalga que possui maior potencial e o sistema de cultivo, bem como as formas para aumentar a porcentagem de carboidrato na célula. Para obter viabilidade econômica na produção de bioetanol de microalgas, a produção deve ser simultânea com produtos de alto valor como pigmentos, proteínas e farmacêuticos obtidos das microalgas em um conceito de biorrefinaria.

\section{Referências}

ABREU, A. P.; FERNANDES, B.; VICENTE, A. A.; TEIXEIRA, J.; DRAGONE, G. Mixotrophic cultivation of Chlorella vulgaris using industrial dairy waste as organic carbon source. Bioresource Technology, v. 118, p. 6166, 2012.

ALBERTS, B.; BRAY, D.; LEXIS, J.; RASS, M.; ROBERT, K.; WATSON, J. D. Biologia Molecular da Célula, 3. ed. Porto Alegre: Artes Médicas, 1997.

AMORIM, H. V.; LOPES M. L.; OLIVEIRA, J. V. C.; BUCKRIDGE, M. S.; GOLDAMAN, G. H. Scientific challenges of bioethanol production in Brazil. Appl Microbiol Biotechnol, v. 91, p. 12671275, 2011.

BALAT, M.; BALAT, H.; ÖZ, C. Progress in bioethanol processing. Progress in Energy and Combustion, v. 34, p. 551-573, 2008.

BARBOSA, H. R.; TORRES, B. B. Microbiologia básica. São Paulo: Atheneu, 1998.
BENSAH, E. C.; MENSAH, M. Chemical Pretreatment Methods for the Production of Cellulosic Ethanol: Technologies and Innovations. International. Journal of Chemical Engineering, v. 2013, p. 21, 2013.

BON, E. P. S.; FERRARA, M. A.; CORVO, M. L. Enzimas em biotecnologia: produção, aplicações e mercado. Rio de Janeiro: Interciência, 2008.

BOROWITZKA, M. A. Culturing microalgae in outdoor ponds. In: ANDERSEN, R. A. (Ed.) Algal culturing techniques. New York: Elsevier Academic, 2005. p. 205-218.

BRÁNYIKOVÁ, I.; MARŠÁLKOVÁ, B.; DOUCHA, J.; BRÁNYIK, T.; BIŠOVÁ, K.; ZACHLEDER, V.; VÍTOVÁ, M. Microalgaenovel highly efficient starch producers. Biotechnol Bioeng., v. 108, n. 4, p. 766-776, 2011.

BRENNAN, L.; OWENDE, P. Biofuels from microalgae - A review of technologies for production, processing, and extractions of biofuels and co-products. Renewable and Sustainable Energy Reviews, v. 14, p. 557-577, 2010.

BRENTNER, L. B., ECKELMAN, M. J.; ZIMMERMAN, J. B. Combinatorial Life Cycle Assessment to Inform Process Design of Industrial Production of Algal Biodiesel. Environmental Science \& Technology, v. 45, p. 7060-7067, 2011.

CANAKCI, M.; SANLI, H. Biodiesel production from various feedstock's and their e Vectson the fuel properties. Journal Industrial Microbiology Biotechnology, v. 35 p. 431-441, 2008.

CARDOZO, K. H. M.; GUARATINI, T.; BARROS, M. P.; FALCÃO, V. R.; TONON, A. P.; LOPES, N. P.; CAMPOS, S.; TORRES, M.A.; SOUZA, M. A.; COLEPICOLO, P.; PINTO, E. Metabolites from algae with economical impact. Comparative Biochemistry and Physiology, v. 146, n.1-2, p. 60-78, 2007.

CARRIQUIRY, M. A.; DU, X.; TIMILSINA, G. R. Second generation biofuels: economics and policies. Energy Policy, v. 39, n. 7, p. 4222-4234, 2011. 
CARVALHO, A. P., MEIRELES, L. A., MALCATA, F. X. Microalgal reactors: a review of enclosed system designs and performances. Biotechnology Progress, v. 22, p. 1490-1506, 2006.

CHAE, S. R.; HWANG, E. J.; SHIN, H. S.; Single cell protein production of Euglena gracilis and carbon dioxide fixation in an innovative photobioreactor. Bioresource Technology, v. 97, n. 2, p. 322-329, 2006.

CHANDER, R. et al. Bioethanol production from pentose sugars: Current status and future prospects. Renewable and Sustainable Energy Reviews, v. 15, p. 4950-4962, 2011.

CHENG, Y.; DENG, S.; HENNESSY, K.; LIN, X.; LIU, Y.; WANG, Y.; MARTINEZ, B.; RUAN, R. Review of the biological and engineering aspects of algae to fuels approach. International Journal of Agricultural and Biological Engineering, v. 2, p. 1-30, 2009.

CHISTI, Y. Biodiesel from microalgae beats bioethanol. Trends in Biotechnology, v. 26, n. 3, p. 126-131, 2008.

. Biodiesel from microalgae. Biotechnology Advances, v. 25, p. 294-306, 2007.

CHOIX, F. J.; DE BASHAN, L. E.; BASHAN, Y. Enhanced accumulation of starch and total carbohydrates in alginate-immobilized Chlorella spp. induced by Azospirillum brasilense: II. Heterotrophic conditions. Enzyme and Microbial Technology, v. 51, p. 300-309, 2012.

DANTAS, M. B.; ALBUQUERQUE, A. R.: SOLEDADE, L. E. B.; QUEIROZ N.; MAIA, A. S.; SANTOS, I. M. G.; SOUZA, A. L.; CAVALCANTI, E. H. S.; BARRO, A. K.; SOUZA, A. G. Biodiesel from soybean oil, castor oil and their blends. Journal of Thermal Analysis and Calorimetry, v. 106, p. 607-611, 2011.

DE CASTRO ARAÚJO, S.; GARCIA, V. M. T. Growth and biochemical composition of the diatom Chaetoceros cf. wighamii brightwell under different temperature, salinity and carbon dioxide levels. I. Protein, carbohydrates and lipids. Aquaculture, v. 246, n. 1-4, p. 405-412, 2005.
DIEN,B.S.;COTTA,M.A.;JEFFRIES,T.W.Bacteria engineered for fuel ethanol production: current status. Applied Microbiology and Biotechnology, v. 63, p. 258-66, 2003.

DOUCHA J.; STRAKA F.; LIVANSKY, K. Utilization of flue gas for cultivation of microalgae (Chlorella sp.) in an outdoor open thin layer photobioreactor. Journal of Applied Physiology, v. 17, p. 403-412, 2005.

DRAGONE, G.; FERNANDES, B. D.; ABREU, A. P.;VICENTE, A. A.; TEIXEIRA, J. A. Nutrient limitation as a strategy for increasing starch accumulation in microalgae. Applied Energy, v. 88, n. 10, p. $3331-3335,2011$

ESCOBAR, J. C.; LORA, E. S.; VENTURINI, O. J.; YANEZ, E. E.; CASTILLO, E. F. Biofuels: environment, technology and food security. Renew. Renewable and Sustainable Energy Reviews, v. 13, p. 1275-1287, 2009.

FERNÁNDEZ, A. F. G.; FERNÁNDEZ S. J. M.; MOLINAG. E. Photobioreactors for the production of microalgae. Reviews in Environmental Science and Biotechnology, v. 12, p. 131-15, 2013.

FRIEDMAN, O.; DUBINSKY, Z.; ARAD, S. Effect of light intensity on growth and polysaccharide production in red and blue-green Rhodophyta unicells. Bioresource Technology, v. 38, n. 2-3, p. 105-110, 1991.

GEIDER, R. J.; LA ROCHE, J. Redfield revisited: variability of $\mathrm{C}: \mathrm{N}: \mathrm{P}$ in marine microalgae and its biochemical basis. European Journal of Phycology, v. 37, n. 01, p. 1-17, 2002.

GIRIO, F. M.; FONSECA, C.; CARVALHEIRO, F.; DUARTE, L. C.; MARQUES, S.; BOGELLUKASIK, R. Hemicelluloses for fuel ethanol: a review. Bioresource Technology, v. 101, n. 13, p 4775-4800, 2010.

GISELRØD, H. R; PATIL, V. K. Towards sustainable production of biofuels from microalgae. International Journal of Molecular Sciences, v. 9, p. 1188-1195, 2008. 
GONG, Y.; JIANG, M. Biodiesel production with microalgae as feedstock: from strains to biodiesel. Biotechnology Letters, v. 33, p. 12691284, 2011.

HAGERDAL, B.; GALBE, M.; GORWAGRAUSLUND, M. F.; LIDEN, G.; ZACCHI, G. Bio-ethanol - the fuel of tomorrow from the residues of today. Trends Biotechnol, v. 24, p. 549-56, 2006.

HAMELINCK, C. N.; VAN HOOIJDONK G.; FAAIJ A. P. C. Ethanol from lignocellulosic biomass: techno-economic performance in short,middle- and long-term. Biomass Bioenergy, v. 28, p. 384-410, 2005.

HARUN, R.; SINGH, M.; FORDE， G. M; DANQUAH, M. K. Bioprocess engineering of microalgae to produce a variety of consumer products. Renewable and Sustainable Energy Reviews, v. 14, p. 1037-1047, 2010.

HARUN, R.; DANQUAHA, M.k. Enzymatic hydrolysis of microalgal biomass for bioethanol production. Chemical Engineering Journal, v. 168, p. 1079-1084, 2011.

HEASMAN, M.; DIEMAR, J.; O'CONNOR, W.; SUSHAMES, T.; FOULKES, L. Development of extended shelf-life microalgae concentrate diets harvested by centrifugation for bivalve mollusks-a summary. Aquaculture, v. 31, n. 8-9, p. $637-659,2000$.

HO, S. H.; CHEN, C. Y.; CHANG, J. S. Effect of light intensity and nitrogen starvation on $\mathrm{CO} 2$ fixation and lipid/carbohydrate production of an indigenous microalga Scenedesmus obliquus CNW-N. Bioresource Technology, v. 113, p. 244-252, 2012.

HO, S. H.; HUANG, S. W, CHEN, C.; HASUNUMA, T.; KONDO, A.; CHANG, J. Bioethanol production using carbohydrate-rich microalgae biomass as feedstock. Bioresource Technology, v. 135, p. 191-198, 2013.

HU, Q. Environmental effects on cell composition. In: Richmond A (ed) Handbook of microalgal culture: biotechnology and applied phycology. Blackwell Publishing Ltd, Oxford, 2004.
HUNTLEY, M. E.; REDALJE, D. G. $\mathrm{CO}_{2}$ Mitigation and renewable oil from photosynthetic microbes: a new appraisal. Mitigation and Adaptation Strategies for Global Change, v. 2, p. 573-608, 2007.

JI, C. F.; YU, X. J.; CHEN, Z.A.; XUE, S.; LEGRAND, J.; ZHANG, W. Effects of nutrient deprivation on biochemical compositions and photohydrogen production of Tetraselmis subcordiformis. International Journal of Hydrogen Energy, v. 36, n. 10, p. 5817-5821, 2011.

JOHN, R. P.; ANISHA, G. S.; NAMPOOTHIRI, K. M.; PANDEY, A. Micro and macroalgal biomass: a renewable source for bioethanol. Bioresource Technology, v. 102 n. 1, p. 186- 193, 2011.

KATAHIRA, S.; MIZUIKE, A.; FUKUDA, H.; KONDO, A. Ethanol fermentation from lignocellulosic hydrolysate by a recombinant xyloseand cellooligosaccharide-assimilating yeast strain. Applied Microbiology and Biotechnology, v. 72, p. 1136-43, 2006.

KHOO, H. H.; SHARRATT, P. N.; DAS, P.; BALASUBRAMANIAN, R. K.; NARACHARISETTI, P. K.; SHAIK, S. Life cycle energy and $\mathrm{CO}_{2}$ analysis of microalgae-to-biodiesel: Preliminary results and comparisons. Bioresource Technology, v. 102, p. 5800-5807, 2011.

LAMMENS, T. M.; FRANSSEN, M. C. R.; SCOTT, E. L.; SANDERS, J. P. M. Availability of proteinderived amino acids as feedstock for the production of bio-based chemicals. Biomass Bioenergy, v. 44, p. 168-181, 2012.

LARDON, L.; HÉLIAS A.; SIALVE, B.; STEYERS, J. P.; BERNARD, O. Life-Cycle Assessment of Biodiesel Production from Microalgae. Environmental Science and Technology, v. 43, p. 6475-6481, 2009.

LEE, Y. K. Microalgal mass culture systems and methods: Their limitation and potential. Journal of Applied Physiology, v. 13, n. 4, p. 307-315, 2001.

LEE, J. Y.; YOO, C.; JUN, S. Y.; AHN, C. Y.; OH, H. M. Comparison of several methods for effective lipid extraction from microalgae. Bioresource Technology, v. 101, p. S75-S77, 2010. 
LEHNINGER, A. L.; NELSON, D. L.; COX, M. M. Princípios de Bioquímica. Tradução de W. R. Loodi, e A. A. Simões. São Paulo: Sarvier, 2000. 839 p. Tradução de: Principles of biochemistry.

LIMA, U. A.; AQUARONE, E.; BORZANI, W.; SCHMIDELL, W. Biotecnologia Industrial: Processos Fermentativos e Enzimáticos. São Paulo: Edgard Blücher, 2001. v. 3.

LYND, L. R.; WEIMER, P. J.; VAN ZYL, W. H.; PRETORIUS, I. S. Microbial cellulose utilization: fundamentals and biotechnology. Microbiology and Molecular Biology Reviews, v. 66, n. 3, p. 506-577, 2012.

MABEE, W. E.; GREGG, D. J.; ARATO, C.; BERLI, A.; BURA, R.; GILKES, N.; MIROCHNIK, O.; PAN, X.; PYE, K. E. SADDLER, J. N.; LESS, S. Updates on softwood-to-ethanol process development. Applied Biochemistry and Biotechnology v. 129, p. 55-70, 2006.

MARGARITES, A. C. F. Sintese de carboidratos por microalgas e produção de bioetanol. Tese de Doutorado no Programa de Pós-Graduação em Engenharia e Ciência de Alimentos da Universidade Federal do Rio Grande. Rio Grande/RS, 2014.

MARIA, E.; MOTTA, M. S.; WALTER, B. S; SANTOS, R. M. P.; MARQUES, O. M.; QUEIROZ, L. A. Capacidade de fermentação de Saccharomyces cerevisiae culturas. Brazilian Archives of Biology and Technology, v. 52, p.819-824, 2009.

MARKOU, G. Alteration of the biomass composition of Arthrospira (Spirulina) platensis. Bioresource Technology, n. 116, p. 533-535, 2012.

MARKOU, G.; ANGELIDAKI, I.; GEORGAKAKIS, D. Microalgal carbohydrates: an overview of the factors influencing carbohydrates production, and of main bioconversion technologies for production of biofuels. Appl Microbiol Biotechnol, v. 96, p. 631-645, 2012.

MIRANDA, J.R.; PASSARINHO, P.C.; GOUVEIA, L. Bioethanol production from Scenedesmus obliquus sugars: the influence of photobioreactors and culture conditions on biomass production. Appl Microbiol Biotechno, v. 196, p. 555-564, 2012.
MOLINA, G. E.; FERNANDEZ, F. G. A.; CHISTI, Y. Tubular photobioreactor design for algalcultures. Journal Biotechnology, v. 92, n. 2, p. 113-131, 2001.

MOLINA, G. E; BELARBI, E. H; FERNANDEZ, F. G. A; ROBLES, M; CHISTI, Y. Recovery of microalgal biomass and metabolites: process options and economics. Biotechnology Advances, v. 20, p. 491-515, 2003.

MOSER, B. R.; VAUGHN, S. F. Biodiesel from Corn Distillers Dried Grains with Solubles: Preparation, Evaluation, and Properties. Bioenergy Research, v. 5, p. 439-449, 2012.

MOSIER, N.; WYMAN, C.; DALE, B.; ELANDER, R.; HOLTZAPPLE, Y. Y. L. M.; LADISCH, M. Features of promising technologies for pretreatment of lignocellulosic biomass. Bioresource Technology, v. 96, p. 673-686, 2005.

MOXLEY, G.; ZHANG, Y. H. P. More accurate determination of acid-labile carbohydrates in lignocellulose by modified quantitative saccharification. Energy Fuels, v. 21, n. 6, p. 3684 3688, 2007.

NAKAMURA, T.; SENIOR, C. L.; OLAIZOLA, M.; BRIDGES, T.; FLORES, S.; SOMBARDIER, L.; MASUTANI, S. M. Recovery and sequestration of CO2 from stationary combustion systems by photosynthesis of microalgae. Final Report, US Department of Energy, pp. 220, 2005.

OGBONDA, K. H.; AMINIGO, R. E.; ABU, G. $\mathrm{O}$. Influence of temperature and $\mathrm{pH}$ on biomass production and protein biosynthesis in a putative Spirulina sp. Bioresource Technology, v. 98, n. 11, p. 2207-2211, 2007.

OLAIZOLA, M. Commercial production of astaxanthin from Haematococcus pluvialis using 25,000-liter outdoor photobioreactors. Journal Applied Phycology, v. 12, n. 3, p. 499-506, 2000.

PROCHÁZKOVÁ, G.; BRÁNYIKOVÁ, I.; ZACHLEDER, V.; BRÁNYIK, T. Effect of nutrient supply status on biomass composition of eukaryotic green microalgae. Journal Applied Phycology, v. 26, p. 1359-1377, 2014. 
RAZEGHIFARD, R. Algal biofuels. Photosynthesis Research, v. 117, p. 207-219, 2013.

REGULY, J. C. Biotecnologia dos processos fermentativos: fundamentos, matérias-primas agrícolas, produtos e processos. Pelotas: Universitária/UFPel, 1996. v. 1.

RICHMOND, A. Microalgal biotechnology at the turn of the millennium: a personal view. Journal Applied Phycology, v. 12, n. 3-5, p 441-451, 2000.

SASSANO, C. E. N.; GIOIELLI, L. A.; FERREIRA, L. S.; RODRIGUES, M. S.; SATO, S.; CONVERTI, A.; CARVALHO, J. C. M. Evaluation of the composition of continuously-cultivated Arthrospira (Spirulina) platensis using ammonium chloride as nitrogen source. Biomass Bioenergy, v. 34, n. 12, p. 1732-1738, 2010.

SAVALIYA, M. L.; DHORAJIYA, B. D.; DHOLAKIYA, B. Z. Recent advancement in production of liquid biofuels from renewable resources: a review. Research on Chemical Intermediates, 2013.

SCHENK, P. M.; THOMAS-HALL, S. R.; STEPHENS, E.; MARX, U. C.; MUSSGNUG, J. H.; POSTEN, C.; KRUSE, O.; HANKAMER, B. Second generation biofuels: high-efficiency microalgae for biodiesel production. Bioenergy Research, v. 1, p. 20-43, 2008.

SILVERSTEIN, R. A. A Comparison of chemical pretreatment methods for converting cotton stalks to ethanol. Master's Thesis (adv: R. Sharma), Biological and Agricultural Engineering, North Carolina State University, 2004.

SIM, S. J.; CHOI, S. P.; NGUYEN, M. T. Enzymatic pretreatment of Chlamydomonas reinhardtii biomass for ethanol production. Bioresource Technology, v. 101, n. 14, p. 53305336, 2010.

SINGH, N. K.; DHAR, D. W. Microalgae as second generation biofuel. A review. Agronomy Sustainable Development, v. 31, p. 31:605-629, 2011.
SKJÅNES, K.; REBOURS, C.; LINDBLAD, P. Potential for green microalgae to produce hydrogen, pharmaceuticals and other high value products in a combined process. Critical Reviews in Biotechnology, p. 1-44, 2012.

SOCCOL, C. R.; VANDENBERGHE, L. P. S.; MEDEIROS, A. B. P.; KARP, S. G.; BUCKERIDGE, M.; RAMOS, P.R.; PITARELO, A. P.; LEITÃO, V. F.; GOTTSCHALK, L. M. F.; FERRARA, M. A.; BON, E. P. S.; MORAES, L. M. P.; ARAÚJO, J. A.; TORRES, F. A. G. Bioethanol from lignocelluloses: status and perspectives in Brazil. Bioresource Technology, v. 101, p. 4820-4825, 2009.

SORATANA, K.; HARPER, W. F.; LANDIS, A. E. Microalgal biodiesel and the Renewable Fuel Standard's greenhouse gas requirement. Energy Policy, v. 46, p. 498-510, 2012.

SOUZA, A. P.; GRANDIS, A.; LEITE, D. C. C.; BUCKERIDGE M. S. Sugarcane as a Bioenergy Source: History, Performance, and Perspectives for Second-Generation Bioethanol. Bioenergy Research, v. 7, p. 24-35, 2014.

STEPHENS, E.; ROSS, I.L.; KING,Z.; MUSSGNUG, J. H.; KRUSE, O.; POSTEN, C.; BOROWITZKA, M. A.; HANKAMER, B. An economic and technical evaluation of microalgal biofuels. Nature Biotechnology, v. 28, p. 126-128, 2010.

STEPHENSON, A. L.; KAZAMIA, E.; DENNIS, J. S.; HOWE, C. J.; SCOTT, S. A. Life-cycle assessment of potential algal biodiesel production in the United Kingdom: a comparison of raceways and air-lift tubular bioreactors. Energy and Fuels, v. 24, p. 40624077, 2010.

THYSSEN, C.; SCHLICHTING, R.; GIERSCH, C. The $\mathrm{CO}_{2}$-concentrating mechanism in the physiological context: lowering the $\mathrm{CO}_{2}$ supply diminishes culture growth and economises starch utilisation in Chlamydomonas reinhardtii. Planta, v. 213, n. 4, p.629-639, 2001.

TREDICI, M. R. Mass Production of Microalgae: Photobioreactors. In: RICHMOND, A (Ed.). Handbook of microalgal culture: biotechnology and applied phycology. Oxford: Blackwell Publishing, p.178-214, 2004. 
TORTORA, G. J.; FUNKE, B. R.; CASE, C. L. Microbiologia. 10. ed. Porto Alegre: Artmed, 2012.

TSIGIE, A. Y.; WUA, C. H.; HUYNH, L. H.; ISMADJ, S.; JU, Y. H. Bioethanol production from Yarrowia lipolytica Polg biomass. Bioresource Technology, v. 145, p. 210-216, 2013.

UGWU, C. U.; AOYAGI, H.; UCHIYAMA, H. Photobioreactorsfor mass cultivation of algae. Bioresource Technology, v. 99, p. 4021-4028, 2008.

VARFOLOMEEV, S. D.; WASSERMAN, L. A. Microalgae as Source of Biofuel, Food, Fodder and Medicines.Apllied Biochemistry and Microbiology, v. 47, n.9, p. 789-807, 2011.

VASUDEVAN, P. T.; FU, B. Environmentally Sustainable Biofuels: Advances in Biodiesel Research. Waste Biomass Valor, v.1, p. 47-63, 2010.

VASUDEVAN, V.; STRATTON, R. W.; PEARLSON, M. N.; JERSEY, G. R.; BEYENE, A. G.; WEISSMAN, J. C.; RUBINO, M.; HILEMAN, J. I. Environmental performance of algal biofuel technology options. Environmental Science \& Technology, v. 46, p. 2451-2459, 2012.

WELLS, M. A.; TUPY, J. L. An electronic companion to biochemistry digital book. New York: Cogito Learning Media 1988.

WORLD ECONOMIC FORUM (WEF). Energy Vision 2013. Energy transitions: Past and Future, 2013.

YEH, K. L.; CHANG, J. S. Nitrogen starvation strategies and photobioreactor design for enhancing lipid content and lipid production of a newly isolated microalga $C$. vulgaris ESP-31: Implications for biofuels. Biotechnology Journal, v. 6, n. 11, p. 1358-1366, 2011.

YEN, H.; HU, C.; CHEN, C. Y.; HO, S. H.; LEE, D. J.; CHANG, J. S. Microalgae-based biorefinery: from biofuels to natural products. Bioresource Technology, v. 135, p. 166-174, 2013.
Recebido em 28 Julho, 2014 - Received on July 28, 2014 Aceito em 30 Outubro, 2015 - Accepted on October 30, 2015 